\title{
Perspective of Consumers and Providers Regarding Services Quality at Accredited and Non Accredited Primary Health Care Centers
}

Asmaa K. Ahmed ${ }^{1}$, Hala R. Yousef ${ }^{2}$, Sahar M. Morsy ${ }^{3}$.

1. Nursing management inspector at Shale Salem health district, Assuit, Egypt.

2. Professor of Nursing Administration Faculty of Nursing Assuit University, Egypt.

3. Professor of Nursing Administration Faculty of Nursing Assuit University, Egypt.

\begin{abstract}
Introduction: Assessment of the quality of care from the consumers and providers perspectives is a fundamental part of quality evaluation. Aim Measuring service quality from perspective of consumers and health care providers in accredited and non accredited primary health care centers at Sahel Seleem health district. Study design: A descriptive comparative. Setting: The study has been conducted in primary health care centers at Sahel Seleem health district. Subjects and Method: The study subjects consisted of two categories (640) consumers and (193) health care providers. The data collected through self- administered questionnaire which include socio demographic data and the service quality model (servperf) developed by (Cronin and Taylor, 1992) . Results: The highest mean scores of consumers perspectives in favor of non accredited centers except in tangibles dimension and health unit characteristic and the highest mean scores of providers perspectives in favor of non accredited centers except in health unit characteristic. Conclusions: There were statistical significant differences between the consumers and the health care providers perspectives in all dimensions except tangibles dimension. Recommendations: Raise consumers and services providers awareness about services quality in the primary health care centers.
\end{abstract}

\section{Key words: Primary Health Care Centers, Service Quality\& Servperf.}

\section{Introduction}

Primary health care (PHC) is the central part of the health system and the significant elementof social and economic growth of each country and they should be equally available to all individuals in the society (Ataee et al., 2016) .

An excellent primary healthcare system leads to a more efficient health system, lower rates of hospitalization and fewer health inequalities. The World Health Report (2008) stated that countries "are not doing as well as they could and as they should" when it comes to primary health care. The main challenge delaying countries from delivering primary health care services are establishing and maintaining high quality services ( Russell, 2009).

Today, many organizations are in search of ways to gain competitive advantage through their products and services which are different from other organization .Providing quality services is the one of the fundamental strategies to accomplish this aim (Mclelland et al., 2014).

The conceptualization of service quality includes both the servicedeliveryprocess and the service outcome. The service outcome is consumer's assessment regarding the result of a service production process, the service delivery process concerns how the end result of the process is conveyed to the customer.This contains the way staff provide and complete their individual tasks, and their service delivery (Siew-Peng Lee \& Sedigheh Moghavvemi, 2015).
Service quality has been defined as the difference between customers wants and what they actually obtain .High level of service quality leads to increase customer satisfaction and also service quality would preserve existing customers, attract new customers, and decrease costs (Laith \& Feras, 2011).

Service quality is a vital issue in the healthcare sector, so that high quality health care service is the first priority of the health sector, due to dealing with life of people, improve the quality of services has unusual importance. Therefore, measurement and management of service quality is critical for healthcare organizations (Jabraeily et al., 2012).

The measurement of service quality can offer specific data that can be used in quality management; hence, service organizations would be able to check and sustain quality service. Assessing service quality and good understanding how different dimensions have an effect on overall service quality would allow organizations to proficiently design the process of service delivery .By detectingstrong point and weakpoint pertaining to the dimensions of service quality organizations can improved allocation of resources to provide better service and ultimately good service to external consumers ( Shahin, 2006). Service qualities depend on the communication between clients and service providers. Customer views about the service provided, service quality or satisfaction, and might be measured. These days, the perception of quality has been changed due to customer awareness. To satisfy such customers, 
service providers must understand the customer want by incorporating the voice of customer (Deoskar $\boldsymbol{\&}$ Aruna 2010).

One increasingly active method for improving quality at the health care institutional level is accreditation. In spite of its routine use in the work course of the majority hospitals globally, in recent times accreditation has been introduced into the primary health care setting in developed countries. This current emphasis on accreditation in primary health care organizations came with the transfer in healthcare policy from hospitals towards protective and primary healthcare sectors (EL-Jardi et al., 2014).

\section{Significance of the study}

Most studies of consumer perspective of quality have been conducted in developed countries. While slight attention has been given to the quality of primary health care services in developing countries. The importance of considering the perspective of the consumers when assessing and designing health care programs is now widely recognized (Hekkink et al., 2003), so thatidentifying the differences between providers and consumers perceptions of service quality is important issue because it reflects what providers believe in quality of services and what level of quality services will satisfy the consumers. In Egypt, few studies have shed light on perception of consumers and providers regarding services quality in primary health care centers, sothe researcher felt necessary to study this phenomena to identify the quality level of actual services perceived by consumers and providers at accredited and non accredited primary health care centers Sahel Seleem health district.

\section{Aim of the study}

The present study was conducted with the aim of measuring service quality from perspective of consumers and health care providers in accredited and non accredited primary health care centers at Sahel Seleem health district.

\section{Research questions}

the current study seeks to answer the following questions:

- What are the differences between consumers and providers perspectives regarding dimensions of quality?

- What are the differences between the level of services quality in accredited and non accredited primary health care centers?

- Which dimension is the best indicator of overall service quality?

\section{Subjects \& Method \\ Technical design}

This design involves the research design, setting, subjects, and data collections tools.

\section{Research design}

The present study was carried out using comparative design.

\section{Study setting}

The present study was conducted in primary health care centers affiliated to Ministry of Health at Sahel Seleem health district divided into five accredited primary health care centers namely : Al-Afadra, AlAwana , Al-Matmar , Al-Nazla Al-Mostagadda , Bowait and five non accredited primary health care centers namely : Al-Gamaila, Al-Shameia, AlGhoraieb, Dair-Tasa, Arab Motair Al-Matmar .

\section{Study subjects}

The sample consisted of two categories: all health care providers (193) (physicians (30), nurses (96), technicians (38), and administrative personnel (31) working in primary health care centers and consumers (640) attended this centers during the period of data collection (six months).

\section{Data collections tools}

The data needed for the study was collected using service quality model (servperf) .

The study tool is a self -administered questionnaire which comprised three parts:

$\mathbf{1}^{\text {st }}$ part related to socio demographic data sheet of consumers: including, name of primary health care centers, age, gender, marital status, occupation, educational qualification, , and cause of visit.

$2^{\text {nd }}$ part related to socio demographic data sheet of health care providers: including, name of primary health care centers, age, gender, occupation, marital status, educational qualification, and years of experience.

$3^{\text {rd }}$ part related to service quality model (servperf) It was developed by (Cronin \& Taylor, 1992) and modified by Musleh, (2011): and adopted by the researcher. It was used to measure the quality of perceived and actual services. It consisted of 28 statement divided into 7 dimensions classified as the following: Tangibles (4 items), Reliability (5 items), Assurance (4 items), Responsiveness (4 items), Empathy (5 items), health unit characteristic (5 items), and satisfaction of service quality (1 item).

Scoring system

The responding scoring system was measured by using 3 point likert scale agree (3), neutral (2), and disagree (1).

Administrative design

Official approval to carry out this study was obtained from the Dean of Faculty of Nursing - Assiut University, The Ministry of Health Representative in Assiut, The director of Sahel Seleem health district 
,The managers of the health centers , and head nurse of each health centers to collect the necessary data .

\section{Operational design \\ Preparatory phase}

This phase consumed about one year from "August 2015 to February 2016", and include reviewing the relevant literatures concerning the study topics to end the proposal of the study. Additionally, Arabic translation of the study tool into Arabic language was done.

\section{Ethical considerations}

The oral agreement was taken from the participants .confidentiality of obtained data was assured, and the purpose, nature, and the aim of the study was explained to all participants before starting of data collections. No risk for study subjects during application of research. Participants have the right to refuse to participate and withdraw from the study without any rational at any time.

\section{Pilot study}

A pilot study had been conducted to test the questionnaire regarding to feasibility and applicability and for time estimation .It applied for 20 health care providers and 84 consumers that represent $10 \%$ of the total sample size. The pilot study data were analyzed using SPSS version 19 (Statistical Package for Social Science).No changes were done after the pilot study, so the subjects included in the pilot study was included in the total study sample.

\section{Data collection tool}

The researcher met with the study participants individually to explain the purpose of the study, and then seek their participation .After obtaining verbal consent to participate in the study, the study tool was given to the study subjects to be filled through a self - administered questionnaire. The study tool took about fifteen minutes. Data collection lasted for 6 months (from March - August 2016).

\section{Statistical design}

Date entry and data analysis were done using SPSS version 19. Data were presented as number, percentage, mean and standard deviation. MannWhitney test was used to compare quantitative variables between two groups and Kruskal Wallis test for more than two groups in case of non-parametric data. P-value considered statistically significant when $\mathrm{P}<0.05$. 


\section{Result}

Table (1): Socio demographic characteristics of the studied consumers at the primary health care centers, $(n=640)$.

\begin{tabular}{|c|c|c|}
\hline Item & No. $(n=640)$ & $\%$ \\
\hline \multicolumn{3}{|l|}{ Age: (years) } \\
\hline$<25$ & 150 & 23.4 \\
\hline $25-<30$ & 218 & 34.1 \\
\hline $30-<35$ & 145 & 22.7 \\
\hline$\geq 35$ & 127 & 19.8 \\
\hline Mean? \pm SD (Range) & \multicolumn{2}{|c|}{$29.49 \pm 7.14(15.0-58.0)$} \\
\hline \multicolumn{3}{|l|}{ Gender } \\
\hline Male & 106 & 16.6 \\
\hline Female & 534 & 83.4 \\
\hline \multicolumn{3}{|l|}{ Marital status } \\
\hline Single & 35 & 5.5 \\
\hline Married & 602 & 94.1 \\
\hline Widow & 1 & 0.2 \\
\hline Divorced & 2 & 0.3 \\
\hline \multicolumn{3}{|l|}{ Occupation } \\
\hline Housewife & 477 & 74.5 \\
\hline Farmer & 23 & 3.6 \\
\hline Employee & 83 & 13.0 \\
\hline Free business & 11 & 1.7 \\
\hline Skilled worker & 16 & 2.5 \\
\hline Unemployed & 20 & 3.1 \\
\hline \multicolumn{3}{|l|}{ Educational qualification } \\
\hline Illiterate & 61 & 9.5 \\
\hline Read \& write & 26 & 4.1 \\
\hline Primary school & 38 & 5.9 \\
\hline Preparatory school & 85 & 13.3 \\
\hline Secondary school & 316 & 49.4 \\
\hline Technical Institute & 47 & 7.3 \\
\hline High education & 67 & 10.5 \\
\hline \multicolumn{3}{|l|}{ Cause of attendance } \\
\hline Pregnancy follow-up & 159 & 27.1 \\
\hline Child follow-up & 118 & 18.4 \\
\hline Child vaccination & 124 & 19.4 \\
\hline Family planning & 95 & 14.8 \\
\hline Emergency services & 80 & 12.5 \\
\hline Outpatient services & 77 & 12.0 \\
\hline Health education & 31 & 4.8 \\
\hline
\end{tabular}


Table (2): Socio demographic characteristics of the studied health care providers at the primary health care centers, $(\mathrm{n}=193)$.

\begin{tabular}{|c|c|c|}
\hline Item & No. $(n=193)$ & $\%$ \\
\hline \multicolumn{3}{|l|}{ Age: (years) } \\
\hline$<25$ & 17 & 8.8 \\
\hline $25-<30$ & 57 & 29.5 \\
\hline $30-<35$ & 30 & 15.5 \\
\hline$\geq 35$ & 89 & 46.1 \\
\hline Mean \pm SD (Range) & \multicolumn{2}{|c|}{$35.67 \pm 10.21(20.0-61.0)$} \\
\hline \multicolumn{3}{|l|}{ Gender } \\
\hline Male & 70 & 36.3 \\
\hline Female & 123 & 63.7 \\
\hline \multicolumn{3}{|l|}{ Occupation } \\
\hline Physician & 19 & 9.8 \\
\hline Nurse & 93 & 48.2 \\
\hline Technician & 44 & 22.8 \\
\hline Administrative & 37 & 19.2 \\
\hline \multicolumn{3}{|l|}{ Marital status } \\
\hline Single & 32 & 16.6 \\
\hline Married & 154 & 79.8 \\
\hline Widow & 6 & 3.1 \\
\hline \multicolumn{3}{|l|}{ Educational qualification } \\
\hline Secondary school & 125 & 64.8 \\
\hline Technical Institute & 38 & 19.7 \\
\hline
\end{tabular}

Table ( 2 cont.,): Socio demographic characteristics of the studied health care providers at the primary health care centers,$(n=193)$.

\begin{tabular}{|l|c|c|}
\hline \multicolumn{1}{|c|}{ Item } & No. $(\mathbf{n = 1 9 3 )}$ & \% \\
\hline High education & 30 & 15.5 \\
\hline Years of experience & \multicolumn{2}{|c|}{} \\
\hline$<10$ years & 66 & 34.2 \\
\hline $10-15$ years & 56 & 29.0 \\
\hline$>15$ years & 71 & $\mathbf{3 6 . 8}$ \\
\hline Mean \pm SD (Range) & $13.84 \pm 8.83(1.0-38.0)$ & \\
\hline
\end{tabular}

Table (3): Mean scores of service quality dimensions as perceived by the study consumer in accredited and non accredited primary health care centers $(n=640)$.

\begin{tabular}{|l|c|c|c|}
\hline \multirow{2}{*}{ Service quality dimensions } & \multicolumn{2}{|c|}{ Primary health care centers } & \multirow{2}{*}{ P-value } \\
\cline { 2 - 4 } & Accredited $(\mathbf{n = 3 3 0})$ & Non-accredited(n= 310) & \\
\cline { 2 - 4 } & Mean + SD & Mean \pm SD & 0.810 \\
\hline \hline 1. Tangibles & $9.10 \pm 1.69$ & $9.04 \pm 2.39$ & $0.000^{*}$ \\
\hline 2. Reliability & $9.66 \pm 1.47$ & $10.30 \pm 1.75$ & 0.762 \\
\hline 3. Responsiveness & $7.20 \pm 1.65$ & $7.35 \pm 2.47$ & $0.000^{*}$ \\
\hline 4. Assurance & $8.35 \pm 1.47$ & $8.87 \pm 1.61$ & 0.342 \\
\hline 5. Empathy & $10.23 \pm 1.34$ & $10.75 \pm 1.94$ & $0.030^{*}$ \\
\hline 6. Health unit characteristic & $11.47 \pm 1.17$ & $11.11 \pm 1.84$ & $0.001^{*}$ \\
\hline 7. Satisfaction of service quality & $1.78 \pm 0.60$ & $1.95 \pm 0.69$ & \\
\hline
\end{tabular}


Table (4): Mean scores of service quality dimensions as perceived $d$ by the study health care provider in accredited and non accredited primary health care centers $(n=193)$.

\begin{tabular}{|c|c|c|c|}
\hline \multirow{3}{*}{ Service quality dimensions } & \multicolumn{2}{|c|}{ Primary health care centers } & \multirow{3}{*}{ P-value } \\
\hline & $\begin{array}{c}\text { Accredited } \\
(n=193)\end{array}$ & $\begin{array}{c}\text { Non-accredited } \\
(\mathbf{n}=\mathbf{1 0 0})\end{array}$ & \\
\hline & Mean \pm SD & Mean \pm SD & \\
\hline 1. Tangibles & $9.30 \pm 2.17$ & $9.39 \pm 2.25$ & 0.717 \\
\hline 2. Reliability & $12.22 \pm 2.03$ & $12.63 \pm 2.05$ & 0.135 \\
\hline 3. Responsiveness & $10.18 \pm 1.73$ & $10.59 \pm 1.57$ & 0.070 \\
\hline 4. Assurance & $10.26 \pm 1.64$ & $10.75 \pm 1.37$ & $0.025^{*}$ \\
\hline 5. Empathy & $12.74 \pm 1.86$ & $13.03 \pm 1.79$ & 0.261 \\
\hline 6. Health unit characteristic & $12.47 \pm 1.94$ & $12.19 \pm 2.00$ & 0.314 \\
\hline 7. Satisfaction of service quality & $2.24 \pm 0.63$ & $2.28 \pm 0.74$ & 0.482 \\
\hline
\end{tabular}

Table (5): Mean scores of service quality dimensions as perceived by the health care providers and the consumers in accredited and non accredited primary health care centers $(n=833)$.

\begin{tabular}{|l|c|c|c|}
\hline \multicolumn{1}{|c|}{ Service quality dimensions } & $\begin{array}{c}\text { consumers } \\
(\mathbf{n = 6 4 0})\end{array}$ & $\begin{array}{c}\text { Health care providers } \\
(\mathbf{n = 1 9 3})\end{array}$ & \multirow{2}{*}{ P-value } \\
\cline { 2 - 4 } & Mean $\mathbf{\text { SD }}$ & Mean \pm SD & \\
\hline 1. Tangibles & $9.07 \pm 2.06$ & $9.35 \pm 2.20$ & 0.097 \\
\hline 2. Reliability & $9.97 \pm 1.64$ & $12.43 \pm 2.05$ & $0.000^{*}$ \\
\hline 3. Responsiveness & $7.27 \pm 2.09$ & $10.39 \pm 1.66$ & $0.000^{*}$ \\
\hline 4. Assurance & $8.60 \pm 1.56$ & $10.51 \pm 1.52$ & $0.000^{*}$ \\
\hline 5. Empathy & $10.48 \pm 1.68$ & $12.89 \pm 1.82$ & $0.000^{*}$ \\
\hline 6. Health unit characteristic & $11.29 \pm 1.54$ & $12.33 \pm 1.97$ & $0.000^{*}$ \\
\hline 7. Satisfaction of service quality & $1.86 \pm 0.65$ & $2.26 \pm 0.69$ & $0.000^{*}$ \\
\hline
\end{tabular}

Table (6): Relationship between educational qualifications of health care providers and service quality dimensions $(\mathbf{n}=193)$.

\begin{tabular}{|c|c|c|c|c|}
\hline \multirow{3}{*}{ Service quality dimensions } & \multicolumn{3}{|c|}{ Educational qualification } & \multirow{3}{*}{ P-value } \\
\hline & $\begin{array}{c}\text { Secondary } \\
\text { school } \\
(n=125)\end{array}$ & $\begin{array}{c}\text { Technical } \\
\text { Institute }(n=38)\end{array}$ & $\begin{array}{l}\text { High education } \\
\qquad(\mathrm{n}=\mathbf{3 0})\end{array}$ & \\
\hline & Mean \pm SD & Mean \pm SD & Mean \pm SD & \\
\hline 1. Tangibles & $9.68 \pm 2.23$ & $8.82 \pm 2.04$ & $8.63 \pm 2.06$ & $0.011 *$ \\
\hline 2. Reliability & $12.70 \pm 1.91$ & $12.08 \pm 2.07$ & $11.73 \pm 2.39$ & 0.051 \\
\hline 3. Responsiveness & $10.69 \pm 1.33$ & $10.16 \pm 1.57$ & $9.47 \pm 2.49$ & $0.040 *$ \\
\hline 4. Assurance & $10.75 \pm 1.31$ & $10.45 \pm 1.37$ & $9.60 \pm 2.13$ & $0.013 *$ \\
\hline 5. Empathy & $13.02 \pm 1.72$ & $12.87 \pm 1.80$ & $12.40 \pm 2.22$ & 0.486 \\
\hline 6. Health unit characteristic & $12.57 \pm 1.87$ & $12.61 \pm 1.90$ & $10.97 \pm 2.01$ & $0.000^{*}$ \\
\hline 7. Satisfaction of service quality & $2.28 \pm 0.71$ & $2.26 \pm 0.64$ & $2.17 \pm 0.65$ & 0.635 \\
\hline
\end{tabular}

Table (1): Showed that a high percent of the consumers were married, female and housewife $(94.1 \%, 83.4 \%$ $\$ 74.5 \%)$ respectively. Slightly below half $(49.4 \%)$ of them graduated from secondary school. (27.1\%) of them attended primary health care units for pregnancy follow up. The mean age of them was (29.49) years old.

Table (2): Showed that a high percent of the health care providers were married, graduated from secondary school and female $(79.8 \%, 64.8 \%$ \& $63.7 \%)$ respectively. Slightly blow half of them worked as a nurse (48. 2\%) and more than one third of them having more than 15 years of experiences. Their mean age was (35.67) years old.

Table (3): Showed that there were statistical significant differences between the study consumer's perspectives in accredited and non-accredited primary health care centers regarding reliability, assurance, health unit 
characteristic and satisfaction of service quality. The highest mean scores of consumers perspectives in favor of non-accredited centers except in tangibles dimension and health unit characteristics $(\mathrm{p} \leq 0.05)$.

Table (4): Showed that there is no statistical significant difference between the study health care providers perspectives in accredited and nonaccredited primary health care centers regarding all dimensions except assurance dimensions. The highest mean scores of health care provider perspectives in favor of nonaccredited centers except in health unit characteristic $(\mathrm{p} \leq 0.05)$.

Table (5): Showed that there was a statistical significant difference between the consumers and the health care providers perspectives in all dimensions except tangibles dimension. From consumers and providers perspectives, health unit characteristic is the best indicators of service quality. The highest meanscores of service quality dimensions in favor of health care providers perspectives $(\mathrm{p} \leq 0.05)$.

Table (6): Showed that the highest mean scores were among secondary school as regard to all dimension of service quality. There were statistical significant differences between educational qualification of health care providers and all dimension of service quality except in reliability, empathy and satisfaction of service quality $(\mathrm{p} \leq 0.05)$.

\section{Discussion}

Providing high-quality care and ensuring consumers complete satisfaction is a challenge that healthcare institutions face globally. Exploring the quality of care from the consumers and providers perspectives is avital part of quality evaluation .The importance of exploring the consumers perspectives of quality of care in order to fulfill consumers needs and expectations at a satisfactory level. Measuring the quality of nursing care from the consumers ' perspective is an essential part in quality evaluation Zhao \& Akkadechanunt, (2011). The study finding revealed that the majority of the study consumers were female and housewives.This might be attributed to female visit health centers for different services, pregnancy follow up, child follow up, and family planning services .This finding consistent with Ataee, et al., (2016) who found that the majority of people visits health centers to receive primary health care services were women and housewives because females utilize these facilities for themselves and for their children.

The study finding revealed that the highest mean scores of consumers perspectives regarding service quality dimensions in favor of non accredited centers. This might be attributed to availability of physicians, good performance of staff and providers in non accredited centers pay attention for customers needs and expectations .This finding was consistent with
Harnagle, (2014) who illustrated that majority of patients are satisfied with the availability of physicians in the hospital during the working hours and that they don't leave the hospital for other duties.

In additionthis finding was consistent with Sack et al., (2011) who studied the relationship between hospitals' accreditation status and patient satisfaction and found that hospital accreditation is a step towards overall quality management and it was not necessarily a vital factor for quality of care.

The study finding revealed that there were statistical significant differences between the consumers and the health care providers perspectives regarding service quality dimensions except tangibles dimension .This might be attributed to both consumers and health care providers perceive lack of material associated with the services and the management of the health centers need to give attention to physical facilities, appearance of personnel, and materials associated with the services. This finding was consistent with Hansen et al., (2008) who mentioned that clients' perceptions of quality were sensitive to physical conditions of the health facility. Service capacity and the availability of equipment were associated with client perceptions of quality and the health centers should give attention to the infrastructure, physical aspect, and material necessary to the services .

In addition this finding was in contrast with Haj-Ali et al., (2014) who evaluate patients satisfaction in accredited and non accredited hospitals and said that patient more satisfied with the hospital's appearance, physical facilities and equipment and rather than the processes and outcomes of care.

The study finding revealed that the highest mean scores of service quality dimensions in favor of health care providers perspectives. This might be attributed to the fear of the health care providers of the accusation of negligence in the performance of the service. This finding was consistent with Kaba et al., (2015) who mentioned that the health staff satisfied with level of service quality provided in primary health facilities due to tendency of health staff to give more favorable answers to keep "a good name" for their facilities or perhaps health staff were complacent of their efforts towards quality of service provided.

The finding of the current study revealed that there was statistical significant differences in health care providers perspectives regarding service quality dimensions according to educational qualification and the highest means scores of all service quality dimensions found among secondary school. This might be attributed to educational level of health care providers influence their assessment of service quality. This finding was agreement with Abiodun, (2006) who mentioned that participant with education above secondary level have higher likelihood of interaction 
with advance health facilities normally associated with tertiary institutions, , therefore they are most likely to possess a more sophisticated view of quality of care, one that encompasses structure, process and outcome of care so that there was difference between the different health care providers categories on the measures of perception of service quality .

\section{Conclusions}

It was conclude that among studied subjects there were statistical significant differences between the study consumers perspectives in accredited and non accredited centers regarding all dimensions except tangibles, responsiveness and empathy dimensions. While, there is no statistical significance differences between the study health care providers perspectives in accredited and non accredited centers regarding all dimensions except assurance dimensions. In addition there was a statistical significant difference between the consumers and the health care providers perspectives in all dimensions except tangibles dimension. Moreover, Consumers perceived insufficient number of physicians (specially female gynecologist), lack of materials and supplies and buying drugs from outside the health centers as barriers of services quality.

\section{Recommendations}

In the light of the study results, the following recommendations are suggested

- Raise consumers and services providers awareness about services quality in the primary health care centers.

- Provide the primary health care centers with sufficient supplies and equipment necessary for improving services quality.

- Use communication skills effectively with consumers to ensure proper quality of services.

- Communicate with decision makers in the ministry of health to provide female physicians in the primary health care centers.

- Manager in accredited centers should pay attention for customers' needs and expectations and adopt complementary measures that aim to improve service quality.

\section{References}

1. Ataee, M., Karami, B., Rrezaei, S., \& Moraddinazar, M., (2016): measurement of quality of primary health services by servqual model, evidence from urban health centers in west of Iran. Research journal of medical sciences $10(5): 454-480$.

2. Abiodun, A., (2006): Users' perceptions of quality of health care provision. A Study of Moba
L. G Unpublished M.Sc. Project, University of Ilorin.

3. Cronin, J., \& Taylor, S., (1992): Measuring service quality: a reexamination and extension. Journal of Marketing, 56: 55-68.

4. Deoskar, Aruna, A., (2010): A Study of Mobile Services From Customers' Perspective.. National Insurance Academy, Pune , 411045 march 2009.fromshodhganga. Inflipnet .com.

5. EL-Jardi, F., Ataya, N., Skaff, R., ,Hemadeh, R., Jaafar, M., Jamal D., Mdeihly, R., \& Sagherian, L., (2014): Impact of accreditation of primary health care centers: Successes, challenges and policy implication as perceived by health care providers and directors in Lebanon. BMC health services research.14:36,http://www.biomed central .com /1472-6963/14/86.

6. Haj-Ali1, W., Bou, L., Natafgi, N., \& Kassak, K., (2014): Exploring the relationship between accreditation and patient satisfaction - the case of selected Lebanese hospitals. international journals of health policy and management .

7. Hansen, P., Peters, D., Viswanathan, K., Rao,. K., Mashkoor, A., \& Burnham, G., (2008): Client perceptions of the quality of primary care services in Afghanistan. Int $\mathbf{J}$ Qual Health Care2008;20:384-91.

8. Hekkink, C., Sixma, H., \& Quote, W., (2003): Hiv: An instrument for assessing quality of hiv care from the patients' perspective. Quality Safety Health Care Journal, 12: 188-193.

9. Jabraeily, M., Rahimi, B., Khodayari, R., Farhodi, G., \& Mohamadi, A., (2012): Assessment of inpatient satisfaction with quality services in training centers of Urmia University of Medical Sciences with the servequal model. Journal of Health Information Management Association. 2012; 7(2):19-24.

10. Kaba, R., Duku, O., Janssens, W., Nketiah, E., Spieker, N., \& Kojo, D., (2015): Comparison of perceived and technical healthcare quality in primary health facilities: Implications for a Sustainable National Health Insurance Scheme in Ghana.

11. Laith, A., \&Feras, A., (2011): The Mediating effect of patient satisfaction in the patients' perceptions of healthcare quality - Patient trust relationship. International Journal of Marketing Studies 2011; 3: 103-27.

12. Mclelland, A., Iverson, M., \& Beninger, R., (2014): the effect of quetiapine (seroqule TM) on conditioned place preference and elevated plus maze tests in rates when administered alone and in combination with (+) - amphetamine. psycopharmacol ., 231: 4349 . 
13. Musleh, A., (2011): Measuring quality level of the actual services perceived by staff and patients in hospitals operating in the city of Qalqilya. Research available at :atiehm yahoo . com ,amusleh@qou.edu

14. Russell, G., Geneau, R., Johnston, S., Liddy, C., Hogg, W., Hogan, K., (2009): Mapping the future of primary healthcare research in Canada: a report to the Canadian Health Services Research Foundation. Canadian Health Services Research; Available at: http://www.chsrf.ca/migrated/pdf/researchReports /commissioned Research/mapping_future_report_2007_e.pdf.

15. Sack, C., Scherag, A., Lutkes, P., Gunther, W., Jockel, K., \& Holtmann, G., (2011): Is there an association between hospital accreditation and patient satisfaction with hospital care? A survey of 37,000 patients treated by 73 hospitals. Int $\mathbf{J}$ Qual Health Care , 23: 278-83. doi: 10.1093/intqhe/mzr011.

16. Shahin, A., (2006): Servqual and model of service quality gap,A framework for determining and prioritizing critical factors in delivering quality services .

17. Siew-Peng, L., \& Sedigheh, M., (2015): The dimension of service quality and its impact on customer satisfaction, trust, and loyalty: A Case of Malaysian Banks,Asian Journal of Business and Accounting 8(2), 2015.

18. Zhao, S., Akkadechanunt, T., (2011): Patients' perceptions of quality nursing care in a chinese hospital. International Journal of Nursing and Midwifery 3: 145-149. 